
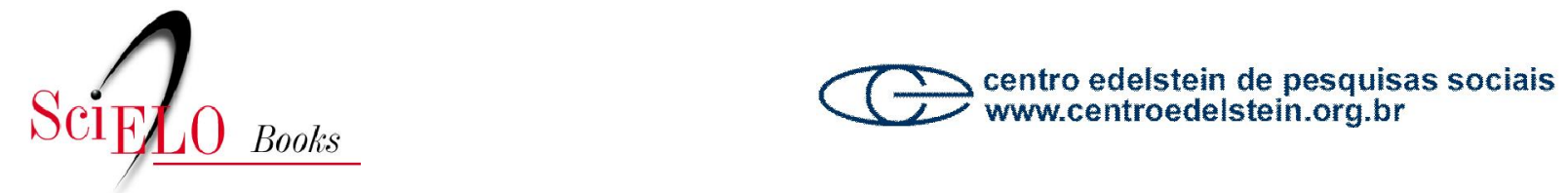

\author{
Anexo \\ os projetos de infra-estrutura e o desenvolvimento regional \\ Fernando Henrique Cardoso
}

SciELO Books / SciELO Livros / SciELO Libros

CARDOSO, FH. Avança, Brasil: proposta de governo [online]. Rio de Janeiro: Centro Edelstein de Pesquisas Sociais, 2008. pp. 162-172. Anexo: os projetos de infra-estrutura e o desenvolvimento

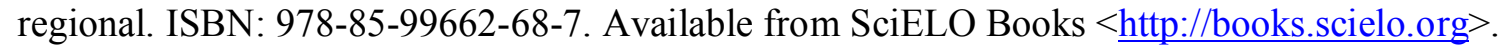

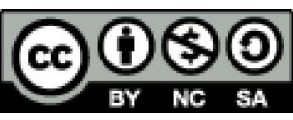

All the contents of this chapter, except where otherwise noted, is licensed under a Creative Commons Attribution-Non Commercial-ShareAlike 3.0 Unported.

Todo o conteúdo deste capítulo, exceto quando houver ressalva, é publicado sob a licença Creative Commons Atribuição Uso Não Comercial - Partilha nos Mesmos Termos 3.0 Não adaptada.

Todo el contenido de este capítulo, excepto donde se indique lo contrario, está bajo licencia de la licencia Creative Commons Reconocimento-NoComercial-CompartirIgual 3.0 Unported. 


\section{ANEXO \\ OS PROJETOS DE INFRA-ESTRUTURA E O DESENVOLVIMENTO REGIONAL}

A definição de uma clara política regional tende a ser um tema básico na agenda das políticas públicas para os próximos anos. O país não conseguirá se integrar ao resto do mundo se não usar como plataforma de crescimento sua própria integração. Ao usá-la, ficará mais forte, atrairá novos capitais externos e deverá expandir sua participação nos mercados internacionais.

$\mathrm{Na}$ medida em que as regiões buscam explorar suas vantagens competitivas em relação aos mercados interno e externo, e as oportunidades se desconcentram, as empresas se tornam mais atuantes em relação às suas decisões de investimento. Vislumbrando oportunidades de mercado, os investidores privados deslocam-se para as diversas regiões e com isso geram renda, emprego e base tributária, propiciando e fortalecendo o processo de descentralização.

É importante, pois, conjugar esforços e recursos dos governos estaduais, municipais e federal, da iniciativa privada e dos financiamentos externos, para aproveitar as vantagens competitivas das diferentes regiões e, desse modo, atender às demandas da sociedade.

Os investimentos em infra-estrutura destacam-se, certamente, como um vetor decisivo de qualquer estratégia de desenvolvimento - e é impensável, no Brasil de hoje, conceber políticas relevantes de investimentos em infra-estrutura sem incorporar a dimensão espacial. Conferir um sentido econômico racional para a distribuição desses investimentos pelo território, transcendendo a geografia política formal, é certamente uma preocupação prioritária.

Cabe ao governo federal estimular ainda mais a distribuição de oportunidades em todas as regiões. Nesse sentido, além dos investimentos estratégicos, o trabalho de detalhar os Eixos Nacionais de Integração e Desenvolvimento deverá apontar um conjunto de investimentos privados que poderão se integrar ao desenvolvimento dessas regiões.

Alguns projetos já foram concluídos ou serão completados até o final de 1998. Outros, em andamento, terminarão nos próximos anos. E já há um primeiro conjunto de projetos definidos para o período 1999/2002, que passarão a ser implementados no próximo ano. Segue-se, depois de uma síntese dos principais empreendimentos regionais, a relação dos projetos em energia e transporte a serem concluídos ou desenvolvidos no âmbito do programa Brasil em Ação nos próximos anos, além daqueles, nos mesmos setores, considerados importantes da perspectiva regional.

\section{Região Norte}

O Norte deve ser visto como espaço para uma expansão inovadora, apoiada no conhecimento e na valorização do patrimônio ambiental. Ali existem oportunidades de novos negócios que respeitam a biodiversidade e lhe agregam valor, em benefício do país e da região.

O desenvolvimento de produtos da indústria química e farmacêutica, resultantes do domínio da biotecnologia, os produtos da floresta tropical obtidos de forma sustentável e o ecoturismo são opções de geração de riqueza que contribuem para conservar a diversidade biológica e cultural, ao mesmo tempo em que integram competitivamente a economia da região ao ambiente econômico internacional.

Também essencial ao desenvolvimento sustentável da região é a construção de uma infraestrutura moderna de transporte, energia e telecomunicações que se integre à natureza amazônica. $\mathrm{O}$ transporte hidroviário é alternativa natural do sistema de transporte da área.

Da mesma forma, energia limpa produzida a partir do gás natural em centrais termelétricas e hidroeletricidade trazida da Venezuela, no quadro da integração energética, além de recursos tecnológicos avançados de controle do espaço aéreo local, são opções já traduzi das em grandes empreendimentos prioritários. 
O Norte oferece novos horizontes à integração com países e blocos de países, como a Bolívia, Venezuela, Guianas e nações do Caribe. Tais oportunidades estão sendo estimuladas, tendo o desenvolvimento sustentável como o motor do progresso econômico e social da região.

Com essa visão de futuro, o governo federal, em parceria com os estados, vem realizando investimentos estratégicos na área, no âmbito do programa Brasil em Ação. Estão sendo concluídas a pavimentação da BR 174, entre Manaus e a fronteira com a Venezuela; a pavimentação da BR 401, entre Boa Vista e a fronteira com a Guiana; e a Hidrovia do Madeira-Amazonas.

Além de programas como o Programa de Biotecnologia da Amazônia - Probem, e o Programa de Desenvolvimento do Ecoturismo na Amazônia - Proecotur, incluídos no programa Brasil em Ação 1999, já está prevista, para o período que vai até 2002, a conclusão ou implementação dos seguintes empreendimentos estratégicos:

\section{Transportes}

\section{Hidrovia do Madeira-Amazonas}

A conclusão do projeto, que já vem operando desde abril de 1997, deve se dar em 1999, após os trabalhos de derrocamento; graças aos investimentos do governo federal, a iniciativa privada construiu terminais portuários em Porto Velho (RO), e Itacoatiara (AM). Este último porto tem calado suficiente para receber graneleiros transoceânicos.

O BNDES financiou a aquisição de barcaças para o transporte de grãos na hidrovia, que deverá reduzir pela metade o custo de transporte da soja produzida em Rondônia e Mato Grosso até o porto de Roterdã, na Holanda.

\section{Hidrovia Tocantins-Araguaia/Ferrovia Norte-Sul/BR 153}

O projeto compreende as hidrovias do Tocantins e do Araguaia. Da Hidrovia do Araguaia, na altura de São Geraldo (PA), parte uma extensão rodoviária em direção a Marabá. Da Hidrovia do Tocantins, na altura de Estreito (MA), parte uma extensão ferroviária (Ferrovia Norte-Sul) em direção a Imperatriz, permitindo assim acesso à Ferrovia de Carajás e ao porto de Itaqui, em São Luís.

Trata-se de um projeto multimodal que permitirá reduzir o custo de transporte dos grãos produzidos na fronteira agrícola de Goiás, Tocantins, Mato Grosso, sul do Maranhão (região de Balsas) e sudoeste do Piauí, bem como diminuir os preços de implementos e equipamentos agrícolas levados para a região.

As hidrovias já estão navegáveis e as obras de balizamento e sinalização estão concluídas. O início das obras de dragagem e derrocamento ainda dependem da obtenção de licenciamento ambiental.

A conclusão do empreendimento deve ocorrer em dezembro de 1999 e já está prevista a construção de um conjunto de duas eclusas na barragem de Tucuruí, tornando navegáveis os 3.600 $\mathrm{km}$ da hidrovia.

\section{Restauração da BR 364}

Trata-se de completar a restauração de cerca de $700 \mathrm{~km}$ de rodovias, nos estados do Acre, Rondônia, Mato Grosso e Mato Grosso do Sul. O fim das obras está previsto para 1999.

\section{Recuperação e pavimentação da BR 317, entre Rio Branco e a fronteira}

Obra incluída no programa Brasil em Ação 1999, essa rodovia, complementar à BR 364, ligará Rio Branco a Brasiléia, na fronteira com a Bolívia, e a Assis Brasil, na fronteira com o Peru. 


\section{Pavimentação da BR 230, ligando Altamira a Marabá}

Obra incluída no programa Brasil em Ação 1999, para ampliar a infra-estrutura da região Norte, integrando-a ao cerrado brasileiro e aos portos da Baía de São Marcos (MA).

\section{Pavimentação da BR 156, ligando Macapá à fronteira com a Guiana Francesa (Oiapoque)}

Obra incluída no programa Brasil em Ação 1999. São 460 km, visando integrar a economia do Amapá e interligar o Brasil por terra à Guiana Francesa.

\section{Cuiabá-Santarém (BR 163)}

Prevista a pavimentação do restante da rodovia, reforçando a ligação entre o Norte e a região Central do país.

\section{Energia}

\section{Gás Natural de Urucu}

Segunda maior reserva de gás do país, vai gerar energia elétrica para os estados de Rondônia, Amazonas e Amapá, sem qualquer dano ao meio ambiente; a produção será de aproximadamente 5 milhões de metros cúbicos/dia de gás natural dos campos de Urucu e Juruá, na Bacia do Solimões.

O gás será transportado desde Urucu até Coari, às margens do rio Solimões, através de um duto de cerca de $280 \mathrm{~km}$ de extensão, e para Porto Velho, através de duto de $500 \mathrm{~km}$. O suprimento de gás para Manaus por gasoduto está sendo estudado pela Petrobrás.

O suprimento de 5 milhões de metros cúbicos de gás por dia permitirá acrescentar $930 \mathrm{~mW}$ ao parque elétrico da região. A conclusão do empreendimento está prevista para o ano 2000.

\section{Linha de transmissão para o aproveitamento da energia de Guri (Venezuela)}

Em junho de 1998, foi assinado contrato com a Corporación Andina de Fomento - CAF, para a construção da linha de transmissão até Boa Vista (RR). O projeto trará para o Brasil mais $200 \mathrm{~mW}$.

\section{Ampliação de Tucuruí}

Instalação de mais onze máquinas, capazes de gerar $375 \mathrm{~mW}$ cada. Com isso, a potência instalada da usina passará de $4.200 \mathrm{~mW}$ para $8.325 \mathrm{~mW}$. A energia adicional estará disponível a partir de 2002.

\section{Hidrelétrica de Manso, no Mato Grosso}

Com capacidade para gerar $210 \mathrm{~mW}$, trata-se de usina transferida à iniciativa privada no âmbito do Programa de Concessão de Obras Paralisadas; são 310 milhões de dólares de investimentos, dos quais $67,8 \%$ de capital privado, com entrada em operação prevista para dezembro de 2001.

\section{Hidrelétrica de Rondon II, em Rondônia}

Com capacidade para gerar $73,5 \mathrm{~mW}$, trata-se também de obra reiniciada, com investimento inteiramente privado de 108 milhões de dólares. Prevê-se a entrada em operação para o final de 2000.

\section{Hidrelétrica de Lajeado, no Tocantins}

Com capacidade de geração de $850 \mathrm{~mW}$, irá mobilizar cerca de 1,1 bilhão de dólares. A entrada em operação está prevista para 2002.

\section{Região Nordeste}

O Nordeste - objeto de um texto específico neste programa - é um espaço de novas 
oportunidades de negócios, renda e emprego em um sem-número de atividades: fruticultura irrigada, turismo, serviços, agropecuária moderna, indústria de transformação. É uma região com tudo para crescer e integrar-se ainda mais ao país e ao mercado internacional, à medida que progredir o suprimento e o gerenciamento dos recursos hídricos em todos os estados da área.

A melhor distribuição da água e a modernização da infra-estrutura de transporte, energia e telecomunicações estão interiorizando o desenvolvimento ainda excessivamente concentrado na faixa litorânea.

Com esse objetivo, enfrenta-se o desafio de mobilizar e capacitar a sociedade local para o progresso econômico, mediante os Pólos de Desenvolvimento Integrado, cuja implantação abrange todos os estados. Empreendimentos nos campos do turismo e da fruticultura, novos e já existentes, serão ampliados para atrair mais investimentos nacionais e estrangeiros.

O Programa de Desenvolvimento do Turismo - Prodetur (a partir do próximo ano, Prodetur II) promove investimentos em infra-estrutura e capacitação profissional capazes de gerar renda e grande número de empregos. O Proágua e o Novo Modelo de Irrigação têm por meta racionalizar e democratizar o uso da água como fator de desenvolvimento e qualidade de vida.

O empreendimento Inovação Tecnológica na Agropecuária, associado ao objetivo do novo modelo de irrigação, representa um esforço mobilizador de pesquisas agrícolas para aumentar o valor agregado da produção irrigada do Semi-árido, conferindo-lhe sustentação econômica.

$\mathrm{Na}$ infra-estrutura, a conclusão da Hidrovia do São Francisco, até o final de 1998, que melhora as condições de navegabilidade nos $1.371 \mathrm{~km}$ entre Pirapora (MG) e a região de Juazeiro (BA)/Petrolina (PE); a construção da Ferrovia Transnordestina; e o término, previsto para 1999, da modernização dos portos de Suape e Pecém estruturam um sistema eficiente de transporte multimodal, que permite falar com todo o realismo em interiorização do desenvolvimento nordestino.

No campo energético, a conclusão da Usina de Xingá, o sistema de transmissão associado a Xingá e os gasodutos Pilar-Cabo e Guamaré-Pecém irão tornar mais competitivas as indústrias instaladas ou em vias de se instalar na região.

É da conjugação desses investimentos estratégicos que está nascendo um novo Nordeste, capaz de ampliar as oportunidades de geração de emprego e renda para seu povo, com uma economia moderna em condições de competir dentro do país e no exterior com produtos e serviços de valor agregado, a exemplo da fruticultura, turismo e serviços.

Nas áreas de transporte e energia, os principais projetos estratégicos em andamento ou a serem desenvolvidos no período 1999/2002 são:

\section{Transporte}

\section{Porto de Suape}

Já em operação, está sendo ampliado. Concluída a dragagem externa, estão avançados os trabalhos da dragagem interna. Trata-se de um projeto integrado, visando à formação de um complexo industrial ao redor do porto. A conclusão do empreendimento está prevista para dezembro de 1999.

\section{Porto de Pecém}

Irá dotar o Ceará de um núcleo de irradiação do desenvolvimento. As obras civis devem ficar prontas em março de 1999.

\section{Ferrovia Transnordestina}


Obra incluída no programa Brasil em Ação 1999. Compreende o trecho Petrolina (PE)/Salgueiro(PE)/Missão Velha (CE); o Ministério dos Transportes examina a possibilidade de delegar a construção à Companhia Ferroviária do Nordeste, atual concessionária da Malha Nordeste.

\section{Energia}

\section{Fortalecimento da interligação Norte-Nordeste}

Foi iniciada a construção da linha de transmissão de 500 kV, entre Presidente Dutra (MA), e Fortaleza (CE). A obra deverá estar terminada em 1999.

\section{Interligação da rede de gasodutos}

Projeto incluído no programa Brasil em Ação 1999, prevê a interligação dos gasodutos da região, com a construção dos trechos entre Pilar (AL) e Cabo (PE) e entre Guamaré (RN) e Pecém (CE).

\section{Região Centro-Oeste}

O cerrado - 90 milhões de hectares agricultáveis -, que se tomou fértil graças à tecnologia agrícola nacional, é a nova fronteira de desenvolvimento econômico do país. Articula-se diretamente com a agroindústria e tem grande capacidade de geração de emprego e renda.

Para tanto, o Centro-Oeste precisa ficar mais perto das demais regiões do país e dos mercados internacionais. O elo que falta é a estruturação de dois eixos que integram o país de norte a sul. O eixo Araguaia- Tocantins e o Eixo do Oeste estreitam os laços econômicos sólidos dentro do país, com a expansão da moderna agroindústria, voltada para os mercados interno e externo.

Por essa razão, os investimentos em curso ampliam a malha multimodal de transporte, de modo a oferecer alternativas de escoamento da produção do cerrado e de internalização de produtos desembarcados em Itacoatiara, Santarém e Belém e, em futuro próximo, São Luís, Suape, Tubarão, Sepetiba, Santos e Paranaguá.

Trata-se, portanto, de um campo promissor para investimentos em energia, telecomunicações e transporte, para sustentar a integração permanente com os mercados nacional e internacional.

É com esse alcance estratégico que estão sendo implantados diversos empreendimentos, como a Hidrovia Araguaia-Tocantins, a restauração da BR 364/163, a Ferronorte, a interligação do sistema elétrico e a duplicação da BR 153/365, ligando Goiânia ao Triângulo Mineiro.

Além de seu potencial produtivo, a região abriga um ecossistema contínuo único no mundo: o Pantanal. É desnecessário dizer que o Pantanal precisa ser preservado e aproveitado, de forma sustentável, para a ampliação do ecoturismo gerador de emprego e renda. Por esse motivo, o governo estabeleceu o Programa de Desenvolvimento Sustentável do Pantanal, envolvendo toda a bacia do Alto Paraguai.

São estes os principais projetos nas áreas de transporte e energia, em andamento ou a serem desenvolvidos de 1999 a 2002:

\section{Transporte}

\section{Ferronorte}

Este projeto tem forte complementaridade com a modernização dos portos de Santos, principalmente, e de Sepetiba, no Rio de Janeiro. 
As obras da Ferronorte foram retomadas em 1996, assegurada a perspectiva de conclusão da ponte rodoferroviária sobre o rio Paraná, ligando Aparecida do Taboado (MS) a Rubinéia (SP). A ponte, uma estupenda obra de engenharia, foi inaugurada em maio de 1998, permitindo o acesso da ferrovia à malha da Fepasa.

Já se tomou a decisão de construir o trecho de $400 \mathrm{~km}$ até Alto Taquari (MT), primeira cidade depois da divisa com Mato Grosso do Sul. A obra deve terminar em 1999. E está prevista a extensão dos trilhos de Alto Taquari até Rondonópolis, no entroncamento com a BR 163. O trecho, de $300 \mathrm{~km}$, deverá estar terminado em 2001.

\section{Ferrovia Unaí-Pirapora}

A obra integrará o corredor de exportação de grãos ligando o Centro-Oeste ao porto de Tubarão. O governo analisa as alternativas de financiamento do projeto.

\section{Duplicação da BR 153/365}

Obra incluída no programa Brasil em Ação 1999, reduzirá o custo de transporte do sul de Goiás e do Triângulo Mineiro ao porto de Santos.

\section{Pavimentação da BR 364}

Obra incluída no programa Brasil em Ação 1999, ligará São Simão (GO) a Frutal (MG), entre os entroncamentos com a BR 153/MG e BR 365/MG.

\section{Energia}

\section{Conclusão do Gasoduto Bolívia-Brasil}

Prevista durante décadas, a obra foi finalmente tocada no governo do presidente Fernando Henrique, contando com empréstimo contratado junto a cinco instituições internacionais (BID, Banco Mundial, Eximbank do Japão, CAF e Banco Europeu de Investimentos), no valor de 800 milhões de dólares.

Calcula-se que o empreendimento esteja atraindo capitais privados para a construção de onze usinas termelétricas, com capacidade de geração de $5 \mathrm{mil} \mathrm{mW}$.

O gasoduto chegará a Campinas (SP) em dezembro de 1998 e ao Rio Grande do Sul em fins de 1999. Em Mato Grosso do Sul atravessará os seguintes municípios: Corumbá, Miranda, Anastácio, Aquidauana, Dois Irmãos do Buriti, Terenos, Campo Grande, Ribas do Rio Pardo, Brasilândia, Santa Rita do Rio Pardo e Três Lagoas.

Haverá pontos de distribuição do gás (city-gates) em Corumbá, Campo Grande, Três Lagoas e, futuramente, em Miranda.

Além desses projetos, são importantes para o desenvolvimento da região:

\section{a. Hidrelétrica de Cana Brava $(G O)$}

Com 450 mW, começará a gerar energia em 2002.

\section{b. Usina Hidrelétrica de Ponte de Pedra (MT/MS)}

Com 180,7 mW, estará operando em 2003.

\section{Região Sudeste}

Ganhar eficiência e competitividade é o desafio da região, para ser capaz de aproveitar as vantagens da fase madura de desenvolvimento e aprofundá-lo com a modernização da logística e 
das telecomunicações.

O desafio interessa a todo o país. Dado o seu estágio de desenvolvimento, o Sudeste se articula com as demais regiões e difunde competitividade à medida que toma mais produtivo o seu sistema econômico.

O descongestionamento das grandes áreas metropolitanas é um aspecto decisivo da questão. É o que tomará possível melhorar o funcionamento do transporte de passageiros e de cargas e, tão importante quanto isso, as condições ambientais.

Os investimentos estratégicos dirigidos para a região foram concebidos exatamente tendo em vista esses problemas. A modernização dos portos de Santos e de Sepetiba facilitam a integração internacional do país, em benefício de todas as regiões, dado que o esforço exportador não exclui nenhuma delas.

O porto de Santos vem passando por amplo processo de modernização. Já foram arrendadas 24 áreas, nas quais há investimentos em curso da ordem de R\$ 546 milhões. Mais 28 áreas serão licitadas nos próximos meses. Devem mobilizar outros $\mathrm{R} \$ 380$ milhões, aproximadamente.

No âmbito do Programa Nacional de Desestatização foi arrendado, em setembro de 1997, o Terminal de Contêineres 1 - TECON 1. O arrendatário assumiu o compromisso de reduzir a taxa de movimentação dos atuais $\mathrm{R} \$ 500$ para $\mathrm{R} \$ 150$ o contêiner. A privatização do Terminal de Contêineres 2 está programada para o início de 1999.

A exemplo dos demais empreendimentos na região, a remodelação dos portos exprime a visão estratégica do governo federal, ao induzir o desenvolvimento do Brasil em seu conjunto, tendo como referência o desenvolvimento regional integrado. O rodoanel, em São Paulo, parte do mesmo princípio, além de representar contribuição de valor incalculável para a melhoria da qualidade de vida na região metropolitana.

Igualmente, a duplicação da Rodovia Fernão Dias e a Rodovia do Mercosul promovem a desconcentração do desenvolvimento, porque irão proporcionar a muitas empresas nas áreas de influência indireta dessas rodovias novas condições de operação, livres, enfim, dos intermináveis engarrafamentos.

A Hidrovia Tietê-Paraná resgatou a modalidade esquecida no Brasil: o uso das vias fluviais. Reduz o custo de transporte e integra várias áreas produtivas, atraindo investimentos e oportunidades em São Paulo, Goiás, Mato Grosso do Sul e Paraná. O empreendimento se integra ao transporte ferroviário e rodoviário, formando um corredor de transporte multimodal - aproveitando o caminhão, o trem e a barcaça justamente onde são mais eficientes ou estão disponíveis.

Outro exemplo ainda é o teleporto no Rio de Janeiro, um centro avançado de telecomunicações para estimular o setor de serviços - uma das vocações mais genuínas da área - e a revitalização urbana da antiga capital.

O gasoduto Bolívia-Brasil, já citado, e o Projeto Cabiúnas aumentarão a oferta de gás natural nas regiões Sudeste e Sul, com as seguintes vantagens: integração energética continental; suprimento de energia limpa; melhoria da qualidade e da produtividade da produção industrial; e abertura de indústrias cujo principal fator de produção é esse tipo de combustível.

Os principais projetos em transporte e energia, boa parte deles executados pela iniciativa privada, em andamento ou a serem desenvolvidos de 1999 a 2002, são os seguintes:

\section{Transporte}

\section{Rodovia do Mercosul}


Em São Paulo, compreende a duplicação da Rodovia Régis Bittencourt, com 236 km em obras e mais 29 km em licitação.

A duplicação dessa estrada deverá terminar em fins de 2000, porque a travessia da reserva de Mata Atlântica, na Serra do Cafezal, exigiu mudanças no traçado original e alterações nos projetos de engenharia. O trecho, portanto, será o último da obra. Ficará a cargo da concessionária privada que assumir a operação da rodovia inteira, cuja licitação já teve início.

\section{Duplicação da Rodovia Fernão Dias}

Faz parte do projeto de consolidação de um corredor rodoviário de integração do Mercosul. O primeiro trecho em Minas Gerais, entre Belo Horizonte e Nepomuceno, de $217 \mathrm{~km}$, já foi inaugurado. O primeiro trecho paulista, de São Paulo até Atibaia $(50 \mathrm{~km})$ deverá estar pronto neste segundo semestre de 1998. A obra toda ficará pronta em 1999.

\section{Rodoanel de São Paulo - Trecho Oeste}

Obra de suma importância para a região metropolitana, incluída no programa Brasil em Ação 1999, reduzirá acentuadamente o custo de transporte das cargas que cruzam a Grande São Paulo, melhorando em muito também a qualidade de vida na região.

Essa primeira etapa, de $32 \mathrm{~km}$, deverá estar concluída no ano 2000; o término da obra inteira, envolvendo mais três trechos (Norte, 39 km; Sul, 40 km; e Leste, 50 km), está marcado para 2004.

\section{Energia}

\section{Gasoduto Bolívia-Brasil}

O gás chegará a Campinas em dezembro de 1998; o gasoduto atravessa 130 municípios, dos quais 71 em São Paulo, com 29 pontos de entrega de gás, treze deles em São Paulo. Em Guararema (SP), o gasoduto se interligará com o sistema da Petrobrás, em benefício de Minas Gerais e do Rio de Janeiro.

\section{Complexo Cabiúnas}

Obra incluída no programa Brasil em Ação 1999, ampliará o sistema de transporte do gás natural produzido na Bacia de Campos para o Rio de Janeiro e, principalmente, Espírito Santo.

\section{Hidrelétrica de Porto Primavera (SP)}

Projeto retomado no âmbito do Programa de Concessão de Obras Paralisadas, mobiliza investimentos de 2,2 bilhões de dólares, dos quais 1,9 bilhão de dólares do setor privado. A usina entrará em operação por etapas ao longo dos próximos anos. Quando estiver em plena operação, no ano 2003, irá gerar $1.814 \mathrm{~mW}$.

Além desses projetos, são importantes para o desenvolvimento da região:

\section{a. Hidrelétrica de Igarapava $(M G)$}

Servindo São Paulo e Minas Gerais, capaz de gerar $210 \mathrm{~mW}$, teve sua construção retomada, com investimentos de 182 milhões de dólares, sendo 156 milhões de dólares do setor privado. Entrada em operação prevista para 1999.

\section{b. Hidrelétrica de Aimorés (MG)}

Outra obra reiniciada. Terá capacidade de geração de $300 \mathrm{~mW}$. Início da operação previsto para 2001.

\section{c. Hidrelétrica de Queimado $(M G)$}


Com 150 mW, entrará em operação em 2001.

\section{d. Termonuclear Angra II (RJ)}

Com capacidade de 1.309 mW, deverá estar concluída em 1999.

\section{e. Termelétrica Eletropaulo I (SP)}

Com capacidade de 450 mW, entrará em operação em 2000.

\section{f. Hidrelétrica de Funil (MG)}

Mais um empreendimento do Programa de Concessão de Obras Paralisadas, deverá gerar 180 $\mathrm{mW}$ a partir de 2001 .

\section{g. Hidrelétrica de Porto Estrela (MG)}

Obra retomada em parceria com o setor privado, irá gerar 112 mW em 2002.

\section{Região Sul}

Aqui as oportunidades de desenvolvimento têm íntima ligação com o Mercosul. Trata-se de saber a melhor forma de aproveitar sua proximidade com grandes mercados externos, mediante aumento do valor agregado da produção, elevação da competitividade de setores industriais e agroindustriais e difusão do desenvolvimento para a faixa de fronteira.

Os empreendimentos na região, tais como a Rodovia do Mercosul, o gasoduto Bolívia-Brasil, antes mencionados, e o porto de Rio Grande, alinham-se estrategicamente com a melhoria das condições sistêmicas de competitividade, redução de custos de transporte e com a introdução do gás natural, fator de melhoria da qualidade e produtividade do parque industrial. Esses fatores são também importantes para a atração de investimentos em novas unidades fabris.

Seguem-se os principais projetos em transporte e energia, vitais para o desenvolvimento regional, que estarão sendo concluídos ou já foram programados para os próximos quatro anos:

\section{Transportes}

\section{Rodovia do Mercosul}

No Sul, compreende a duplicação das seguintes estradas: BR 116, entre a divisa de São Paulo com o Paraná e Curitiba, incluído o contorno leste da capital paranaense; BR 376/101, de Curitiba à divisa com Santa Catarina; BR 101, dali até Florianópolis; e BR 101, de Florianópolis a Osório, no Rio Grande do Sul.

Os recursos para a duplicação desse último trecho vêm sendo negociados com o BID e o Eximbank do Japão. Tais instituições já financiam a duplicação dos trechos São Paulo/Curitiba e Curitiba/Florianópolis. O empreendimento total estará pronto em fins de 2000. O trecho Osório/Porto Alegre, já duplicado, foi concedido à iniciativa privada.

O programa Brasil em Ação 1999 inclui a modernização da BR 290, que liga Porto Alegre a Uruguaiana, na fronteira com a Argentina. E já está prevista a restauração e ampliação do trecho Porto Alegre-Jaguarão (BR 116).

\section{Modernização do porto de Rio Grande}

Obra incluída no programa Brasil em Ação 1999. Consiste em aprofundar de quatorze para dezoito metros o canal de acesso e em estender as malhas de proteção. Os trabalhos deverão estar concluídos no ano 2000. 


\section{Energia}

\section{Gasoduto Bolívia-Brasil}

O gasoduto chegará em 1999 a Canoas (RS), onde fica a Refinaria Alberto Pasqualini.

Outros projetos importantes para o desenvolvimento da região, a entrar em funcionamento entre 1999 e 2002:

\section{a. Integração energética com a Argentina: interligação elétrica}

Em maio de 1998, a Gerasul, empresa da Eletrobrás, assinou contrato de compra de eletricidade produzida na Argentina, que adicionará mil mW de potência firme ao sistema elétrico brasileiro.

Do lado brasileiro, será necessária a construção de uma usina conversora em Guarabi, na fronteira, e de uma linha de transmissão de $360 \mathrm{~km}$ até a subestação de Há, em Santa Catarina. O investimento, a cargo de um consórcio privado, alcança R \$ 320 milhões. Prevê-se a conclusão da obra para o início do ano 2000.

\section{b. Integração energética com a Argentina: gás natural}

A Petrobrás e a CEEE/RS assinaram contrato com a YPF Argentina e a Transportadora de Gás del Norte para compra de gás natural em duto. A operação permite construir uma termelétrica em Uruguaiana, com $600 \mathrm{~mW}$, a entrar em funcionamento em 1999.

Está prevista a extensão do gasoduto até Porto Alegre, devendo acrescentar 3 milhões de metros cúbicos à oferta de gás na região a partir de 2001.

\section{c. Integração energética com o Uruguai}

A primeira etapa consiste na instalação de um conversor de freqüência entre Rivera e Santana do Livramento (RS). O projeto deverá estar concluído no ano 2000 , acrescentando $70 \mathrm{~mW}$ ao parque elétrico nacional.

Estuda-se a captação de gás natural uruguaio e a construção de uma termelétrica em Livramento, com $500 \mathrm{~mW}$. O projeto está a cargo da Gerasul.

\section{d. Hidrelétrica de Itá (SC)}

Com $1.450 \mathrm{~mW}$, integra o Programa de Concessão de Obras Paralisadas. A construção foi retomada, com aporte de 865 milhões de dólares, sendo 750 milhões de dólares do setor privado. A entrada em operação está prevista para 2000.

\section{e. Hidrelétrica de Salto Caxias (PR)}

Com $1.240 \mathrm{~mW}$, integra o Programa de Concessão de Obras Paralisadas. A construção foi retomada, com aporte de 784 milhões de dólares, sendo 411 milhões de dólares do setor privado. Prevê-se para 1999 a entrada em operação.

\section{f. Hidrelétrica de Machadinho (RS)}

Servindo também Santa Catarina, com $1.140 \mathrm{~mW}$. Obra retomada, com investimentos de 839 milhões de dólares, dos quais 785 milhões de dólares do setor privado. Entrada em operação prevista para 2003.

\section{g. Hidrelétrica de Itaipu $(P R)$}

Implantação das unidades 19 e 20 da usina, elevando a capacidade de geração em 1.400 mW; entrada em operação da primeira etapa prevista para 2001.

\section{h. Hidrelétrica de Campos Novos (SC)}

Com 880 mW de potência. Primeira fase da operação prevista para 2002. 


\section{i. Termelétrica de Uruguaiana (RS)}

Com 600 mW e entrada em operação prevista para 1999, deverá utilizar gás da Argentina. j. Hidrelétrica Dona Francisca (RS)

Capacidade de geração: 125 mW. Entrada em operação prevista para 2001.

k. Termelétrica de Jacuí (RS)

Com 350 mW de capacidade, entrará em operação em 2002. 